Saiz Linares, A. \& Ceballos López, M. (2021). Indagación biográfica, photovoice y escritura reflexiva en el prácticum de futuros docentes. Revista Electrónica Interuniversitaria de Formación del Profesorado, 24(1), 43-58.

\title{
Indagación biográfica, photovoice y escritura reflexiva en el prácticum de futuros docentes
}

Ángela Saiz Linares, Noelia Ceballos López

Universidad de Cantabria

\section{Resumen}

Presentamos un estudio de caso evaluativo sobre una propuesta formativa en los Grados de Maestro de la Universidad de Cantabria, articulado sobre asuntos pedagógicos que los estudiantes seleccionan y confrontan reflexivamente. Se sustenta en las posibilidades formativas de la escritura reflexiva, la exploración biográfica y la metodología de Photovoice. Los instrumentos de recogida de información son: grabaciones de audio y transcripción de seminarios, diarios de investigación y de prácticas y fotografías tomadas por los alumnos. Desarrollamos un análisis de contenido que evidencia el potencial de la propuesta formativa para registrar asuntos son relevantes del desempeño docente, destacando su grado de heterogeneidad; promover el diálogo crítico a través de la negociación de significados de las imágenes; analizar y reorientar la acción y el pensamiento docente. Concluimos reflexionando sobre la virtualidad de las imágenes pedagógicas tomadas por los propios estudiantes y la deliberación colaborativa para convertirse en palancas de formación docente.

Palabras clave

Practicum de magisterio; indagación biográfica; photovoice; escritura reflexiva.

\section{Biographical inquiry, photovoice and reflective writing in the pre-service teachers' practicum}

\section{Abstract}

We present an evaluative case study on a training proposal in the Degrees of Teaching of the University of Cantabria that is articulated on dilemmatic situations that the students must 
confront reflectively. This formative proposal is based on the formative possibilities of writing, biographical exploration and the methodology of Photovoice. The instruments for gathering information are: audio recordings and transcriptions of seminars, the student diaries and the photographs taken by the students. We carry out a content analysis that demonstrates the potential of the training proposal to record those issues that are relevant to their teaching performance; promote critical dialogue and shared knowledge through the negotiation of meanings of the images made; analyze and reorient teaching action and thinking. In this way, images and collaborative reflection become powerful levers of teacher training.

\section{Key words}

Teaching practicum; biographical inquiry; photovoice; reflective writing.

\section{Introducción}

Presentamos una innovación en educación superior realizada con estudiantes de practicum de los grados de Educación Primaria y Educación Infantil (Universidad de Cantabria). Sabemos que las prácticas constituyen una experiencia valorada por el alumnado y una ocasión insustituible para el aprendizaje de la profesión de maestro (Kilgo, Sheets y Pascarella, 2015; Sorensen, 2014), que les permite familiarizarse con la cultura de la profesión y conocer internamente la «comunidad de práctica» (Wenger, 2001). Asimismo, constituye un espacio excepcional para que confronten sus teorías con las realidades educativas que van a vivir, contextualizando y resituando el aprendizaje desarrollado en su formación universitaria. Pero, sobre todo, las prácticas suponen un momento clave para que los estudiantes reflexionen sobre sus acciones y se "pongan en juego en primera persona" (Sierra, Caparrós, Molina y Blanco, 2017, p. 676). Considerando este espacio de posibilidades, proponemos una iniciativa de practicum que camina hacia nuevas maneras de formación reflexiva y participativa (Beavers, Orange y Kirkwood, 2017; Wong, 2016; Zeichner, 2005). Partimos, para ello, de dos mástiles formativos que se ponen en juego a través de la escritura de los diarios: la exploración de la biografía (Clandinin y Connelly, 2000; Saiz y Susinos, 2017; Williams y Grierson, 2016) y la metodología de Photovoice (Prins, 2010).

Para nosotras, la formación de futuros maestros tiene que constituirse en experiencia que les implique subjetivamente. Para construir conocimiento, para poder abrirnos a lo nuevo, necesitamos conectarlo con lo que somos, estableciendo una relación de pensamiento respecto a aquello que se vive (Sierra et al., 2017). Si no partimos de la exploración de uno mismo, corremos el riesgo de que los nuevos conocimientos y experiencias no dejen apenas sedimento. Son muchos los autores que señalan la trascendencia de la biografía de los profesores en la configuración de sus teorías pedagógicas (Clandinin y Connelly, 2000; Kelchtermans, 2009). Los años de escolarización no son inocuos y generan creencias implícitas muy poderosas sobre la enseñanza, el aprendizaje y la condición de profesor y de alumno. Explicitar y comprender dichas biografías es fundamental para afrontar una formación de maestros que contribuya a promover aprendizajes que alteren las prácticas tradicionales de enseñanza en las que, por lo general, los estudiantes de magisterio se han socializado o, como señalan Rivas, Leite y Cortés (2014) «para provocar una experiencia transformadora desde un proceso de reflexión crítica» (p. 15).

Por su parte, la Photovoice emerge como una metodología de investigación participativa cuyo valor reside en sus posibilidades de dar voz a aquellos que tradicionalmente son excluidos en los procesos de sociales y de investigación (Prins, 2010; Wang y Burris, 1994). En 
el contexto formativo se ha utilizado como herramienta de reflexión y mejora (Cook y Buck, 2010; Edwards, Perry, Janzen y Menzies, 2012; Lichty, 2013). Esta estrategia permite a los alumnos registrar y visualizar, a través de fotografías, sus ideas, preocupaciones e interpretaciones. En un segundo momento, las fotografías se convierten en objetos de análisis y construcción de conocimiento a través de estrategias de diálogo, reflexión, crítica e intersubjetividad (Bautista, Rayón y de las Heras, 2018; Novak 2010; Parrilla, Raposo, Martínez-Figueira y Doval, 2017).

Para estas finalidades de indagación y reflexión, los diarios brindan posibilidades epistémicas, en tanto la escritura supone un proceso constante de integración del pensamiento, las subjetividades y la representación (Gale y Wyatt ,2007). La escritura va mucho más allá del registro, permitiendo construir ideas y expresar la experiencia encarnada (Sierra et al., 2017). Así, diversos autores (Beavers, Orange y Kirkwood,2017; Eksi y Güngör, 2018; Gan y Lee, 2015; Susinos y Saiz, 2016; Vassilaki, 2017) dan cuenta de las virtualidades de escribir un diario para: analizar las situaciones pedagógicas ocurridas en aras de reevaluar la experiencia; relacionar las informaciones nuevas con lo que ya se conoce; conectar la teoría con la práctica; repensarse a sí mismos y a sus prácticas fuera de la inminencia de la acción; capturar la reflexión en acción y proporcionar un medio para reflexionar conscientemente sobre los supuestos implícitos.

En nuestra propuesta, la escritura se utiliza como método indagatorio (Richardson y St. Pierre, 2005), entendiendo que esta no es únicamente un modo de reflejar conclusiones, sino un medio para construir conocimiento sobre uno mismo y sobre el mundo. Con este sentido indagatorio, escribir también significa documentar diferentes contextos: las actividades diarias, las conversaciones, las interacciones, pero también hacia dentro de sí mismos: sus impresiones, emociones, incluso sueños (Badenhorst et al., 2016). En definitiva, la escritura se utiliza para dar sentido, teorizar y producir conocimiento (Richardson y St. Pierre, 2005), posibilitando relatar la experiencia, pero, sobre todo, hacer experiencia (Contreras y Pérez de Lara, 2010).

\section{Descripción de la propuesta formativa}

Las fases de desarrollo se inspiran en los movimientos que fundamentan la propuesta: la indagación biográfica, la photovoice y la narración escrita que se materializa en el diario.

(1) Definir el asunto de indagación

Durante el primer período de estancia en el centro de prácticas, cada docente en formación selecciona libremente el asunto de indagación bajo la consigna: ¿ qué asuntos de tus prácticas te preocupan o sobre cuáles desearías saber más? Si bien pudieran coincidir diferentes alumnos en un mismo tema, la pertenencia a contextos diversos permitirá un análisis situado y divergente en cada caso. Una vez seleccionado el asunto inician un primer momento de análisis a través de una aproximación escrita guiada por los interrogantes: ¿qué llama mi atención durante estas prácticas? ¿Por qué? ¿Qué conozco sobre este asunto? ¿Qué preguntas realizó sobre el mismo?

\section{(2) Indagación biográfica}

Peirce (1986) explica que los asuntos que consideramos relevantes padecen una interpretación inicial mediada por las experiencias personales, familiares, sociales, escolares, etc. (Bautista, Rayón y de las Heras, 2018). Siguiendo a Conklin (2008), se propone a los alumnos realizar un análisis autobiográfico sobre el asunto. Cada participante decide el modo 
en el que quiere presentarla: atravesando todas las etapas educativas; a través de incidentes críticos, etc.

(3) Desarrollo de la técnica de Photovoice.

En un primer momento, los aspirantes a docentes asisten a dos seminarios de formación sobre la estrategia de Photovoice. El primero versa sobre los aspectos técnicos y estéticos de la elaboración de las fotografías. Si bien prevalece el mensaje sobre los aspectos estéticos, se ofrecieron algunas claves sobre el proceso de toma de fotografías: la necesidad de atender a la luz y el contraste y los encuadres y enfoque.

El segundo seminario se realizó en torno a los aspectos éticos irrenunciables del trabajo (Wang y Redwood-Jones, 2001): explicar a las personas del contexto el sentido de este trabajo y el papel de las imágenes en el mismo con el propósito de obtener su consentimiento informado; asegurar el anonimato y no realizar imágenes ofensivas o degradantes para ninguna persona.

Una vez finalizada la fase de formación, se inicia la indagación sobre el asunto a partir de fotografías. Cada participante, durante su estancia en el centro, realiza fotografías que recogen los elementos clave de los asuntos pedagógicos elegidos.

Los participantes deciden la intencionalidad de sus imágenes: mostrar cambios en el tiempo, ejemplificar relaciones, señalar incidentes, etc. Esta toma de imágenes es desarrollada durante un tiempo prolongado (15-20 días), con la consigna de que pueden realizar un número infinito de imágenes. Es en un momento posterior cuando seleccionan las 10 imágenes más representativas. Acompañando a cada imagen elegida redactan una primera narración interpretativa, animados por las siguientes preguntas:

- Describe tu fotografía

- ¿Qué está ocurriendo?

- ¿Por qué la tomaste? ¿Qué significa para ti?

- ¿Qué nos dice esa fotografía acerca de la escuela?

- ¿Cómo puede esa fotografía servirnos de oportunidad para mejorar la escuela?

\section{(4) Narración compartida}

Tras este primer momento de reflexión individual, se configura un espacio de diálogo compartido: un seminario de trabajo. Cada participante pone a disposición del grupo el documento generado que recoge las imágenes seleccionadas y la narración de las mismas. Este seminario está conformado por todos los alumnos participantes, por lo que responde a la diversidad de la muestra señalada. En este momento, durante diferentes sesiones, cada asunto de indagación es sometido a diálogo, negociación y análisis compartido, donde las imágenes se convierten en elicitadoras de la reflexión conjunta (Bautista, Rayón y de las Heras, 2018). Se facilita a los participantes las siguientes preguntas como generadoras de diálogo:

- ¿Qué ves en las fotografías?

- ¿Qué está sucediendo?

- ¿Cómo se relaciona con tus conocimientos y vivencias pedagógicas?

- ¿Por qué está ocurriendo eso?

- ¿Cómo podría esa imagen servir/educar a otros? 
Este proceso permite que, al final de la sesión, cada participante disponga de preguntas y reflexiones generadas en grupo sobre su tópico, así como de algunas lecturas, propuestas por los compañeros o por los supervisores, que les permitan seguir profundizando en el tema y alcanzar un discurso más complejo sobre el asunto pedagógico.

\section{(5) La construcción de narrativas escritas}

Finalmente, elaboran una narración en clave interpretativa que incorporan a sus diarios de prácticas. Este documento se presenta como resultado del proceso anteriormente descrito $y$, por tanto, se ve enriquecido por las ideas, sugerencias, interpretaciones y análisis llevados a cabo en el seminario de trabajo. Finalmente, exponen en un seminario grupal las conclusiones a las que han llegado sobre su dilema.

\section{Metodología}

La investigación desarrollada durante los cursos 2016-2017 y 2017-2018 se afinca metodológicamente en los pilares de la tradición cualitativa (Flick, 2014) y, más concretamente, dentro del estudio de caso evaluativo (Simons, 2011). Esta metodología posibilita alcanzar un conocimiento profundo y situado sobre el funcionamiento de nuestra propuesta sirviendo al propósito, en última instancia, de profundizar en la comprensión de cómo los sujetos participantes experimentan e interpretan dicha experiencia formativa (Rapley, 2014).

De manera más concreta los objetivos de este trabajo son:

- Conocer los asuntos pedagógicos que preocupan a los maestros en formación.

- Indagar acerca del papel de la biografía escolar de los maestros en formación en la elección y definición de sus asuntos pedagógicos.

- Comprender en qué medida la estrategia de Photovoice permite desarrollar procesos reflexivos con los maestros en formación.

- Analizar la evolucionan de los procesos reflexivos de los maestros en formación a partir de las estrategias reflexivas desplegadas.

Se ha optado por un muestreo intencional que permitiera cubrir el campo de estudio lo más ampliamente posible atendiendo a la pertinencia, adecuación y posibilidad de acceso. Más concretamente, los criterios de selección fueron:

- Las especialidades de formación: Educación Infantil y Educación Primaria.

- Diferentes cursos $\left(2^{\circ}, 3^{\circ}\right.$ y $\left.4^{\circ}\right)$ en ambos grados. Esto permitió una estancia prolongada en los centros educativos de entre 2-4 meses.

- Ubicación geográfica del centro donde desarrollan las prácticas: centros en contextos urbanos, rurales y semiurbanos.

- Titularidad de los centros: centros públicos, centros concertados (cooperativas educativas o de entidad religiosa, siendo estos últimos los más abundantes en Cantabria).

Finalmente, ante nuestro interés expreso de configurar una propuesta sostenible y potencialmente replicable por otros docentes, y también de desplegar todas las posibilidades reflexivas de los seminarios, fue nuestro interés reunir a un grupo de alumnos relativamente pequeño, coincidiendo con el número de alumnos en prácticas que normalmente supervisan 
los docentes de la Universidad de Cantabria (4-5 alumnos). De esta forma, han participado un total de 17 alumnos (tres grupos de 4 alumnos y un grupo de 5 alumnos) y dos supervisoras.

Hemos utilizado instrumentos de producción de datos (Kvale, 2011) que permiten un tratamiento cualitativo de la información:

1. Documentación, a través de grabaciones de audio y notas de campo, de los seminarios. Estos fueron transcritos y facilitados a los participantes para su reafirmación o matización.

2. Diarios de investigación resultantes de las notas de campo.

3. Análisis documental de: la primera versión de la definición del asunto de indagación; el texto que conecta dicho asunto con su biografía escolar; las imágenes y textos generados a partir de la Photovoice; el diario de prácticas, entendido como el documento que resulta de todo el proceso de formación en relación al asunto de indagación.

Los datos obtenidos fueron sometidos a un análisis de contenido a través de un sistema de codificación temática en el que definimos las categorías de análisis y los códigos a partir de estrategias de tipo inductivo y deductivo (Gibbs, 2012).

\section{Resultados y discusión}

En este apartado presentamos los resultados del trabajo dando respuesta a cuatro interrogantes:

\section{¿Qué asuntos pedagógicos interpelan/preocupan a los maestros en formación?}

La siguiente tabla presenta algunos asuntos pedagógicos ${ }^{1}$ elegidos por los participantes que ilustran la amplia heterogeneidad de intereses que atesoran los estudiantes de magisterio, corroborando los hallazgos realizados en anteriores investigaciones (Saiz y Susinos, 2017):

Tabla 1.

Asuntos pedagógicos elegidos por los maestros en formación

\begin{tabular}{lll}
\hline $\begin{array}{l}\text { Asuntos } \\
\text { indagación }\end{array}$ & de & Formulación de la temática \\
\hline Metodología & $\begin{array}{l}\text { "En este centro se utiliza la propuesta pedagógica Pompas de } \\
\text { Jabón, de una editorial. Esta propuesta contiene todas y cada una } \\
\text { de las indicaciones necesarias tanto para maestros como para } \\
\text { padres. Está todo organizado, clasificado y planificado". }\end{array}$ \\
\hline $\begin{array}{l}\text { Resolución } \\
\text { conflictos }\end{array}$ & de & $\begin{array}{l}\text { "Los niños de Infantil están todo el día peleándose y pegándose y } \\
\text { la maestra no sabe cómo gestionar la situación". }\end{array}$ \\
\hline $\begin{array}{l}\text { Atención } \\
\text { Diversidad }\end{array}$ & la & $\begin{array}{l}\text { "Adaptar la educación a cada alumno y ofrecer una atención } \\
\text { individualizada es una tarea compleja, teniendo en cuenta las } \\
\text { ratios tan elevadas que tenemos; por lo que me propongo } \\
\text { investigarlo como un reto personal”. }\end{array}$
\end{tabular}

\footnotetext{
1 Se han elegido estos siete asuntos pedagógicos por sintetizar representativamente el abanico de dilemas
} elegidos por la totalidad del grupo de alumnos participante en la propuesta de practicum. 


\begin{tabular}{ll}
\hline Procesos de cambio & $\begin{array}{l}\text { "El primer dilema resulta algo peculiar. Fui alumno de este mismo } \\
\text { escolares }\end{array}$ \\
& $\begin{array}{l}\text { colegio, y en los años que no he estado se han realizado muchos } \\
\text { ciertas áreas del centro. He decidido orientar este trabajo a los } \\
\text { cambios en las aulas y espacios". }\end{array}$ \\
\hline Materiales & $\begin{array}{l}\text { "En este centro he podido observar que no utilizan un único } \\
\text { material de apoyo aunque sí que se centran básicamente en uno, } \\
\text { las fichas de las diferentes asignaturas". }\end{array}$
\end{tabular}

\begin{tabular}{|c|c|}
\hline $\begin{array}{l}\text { Actividades } \\
\text { complementarias }\end{array}$ & $\begin{array}{l}\text { "Dado que la primera semana ha consistido principalmente en la } \\
\text { preparación del carnaval y teniendo además dos salidas } \\
\text { programadas para la segunda semana, he decidido elegir el tema } \\
\text { de las actividades complementarias". }\end{array}$ \\
\hline Contenidos escolares & $\begin{array}{l}\text { "Me centraré en el análisis de cómo se trasmite la información y } \\
\text { la cultura a los niños/as. Hemos dado en algunas asignaturas que } \\
\text { los contenidos tienden a presentarse infantilizados pero me } \\
\text { gustaría saber más sobre cuáles son las causas y consecuencias de } \\
\text { esa infantilización, así como averiguar cómo minimizar su } \\
\text { impacto". }\end{array}$ \\
\hline
\end{tabular}

Se observa cómo algunos asuntos florecen de la observación directa de las actividades de aula (actividades complementarias, metodología y materiales) y otros se centran en aspectos educativos más amplios, implicando a más miembros de la comunidad educativa y ligados a la construcción de un proyecto educativo de centro (la atención a la diversidad). Otros asuntos, como el de la infantilización de los contenidos escolares, incorporan criterios sociopolíticos a la reflexión sobre la actividad educativa. Sin embargo, advertimos también que hay asuntos (por ejemplo, los procesos de cambio escolares) que, si bien podrían ofrecer una excelente oportunidad de reflexión, en su formulación inicial se concretan únicamente en aspectos extracurriculares (infraestructuras, horarios, etc.). En otras palabras, se presenta como ocasión desaprovechada para repensar colectivamente asuntos esenciales de la vida escolar, ciñéndose a objetos que, si bien son relevantes, no son centrales en la definición del proyecto pedagógico de la escuela. Por último, es necesario destacar la elección de algún tópico (resolución de conflictos) que responde al interés preferente de los maestros en formación de acceder a un conjunto de técnicas que les permitan desarrollar una enseñanza “eficaz" y resolver problemas prácticos del día a día (Mule, 2006; Saiz y Susinos, 2017).

En cualquier caso, la reflexión a partir de asuntos pedagógicos identificados por ellos mismos ha evidenciado su potencial para favorecer la capacidad de análisis y reflexión y, sobre todo, para abrir posibilidades al pensamiento y a la discusión colectiva (Sierra et al., 2017). Así, concentrar la atención sobre un tema de su experiencia cotidiana en las prácticas permite evitar la dispersión que supondría observar y reflexionar sobre todas las cosas y, sobre todo, posibilita problematizar dicho asunto, esto es, cuestionarlo desde diferentes ángulos para analizarlo y comprenderlo profundamente. 


\section{¿Cuál es el papel de la biografía escolar en la definición de los asuntos pedagógicos?}

En primer lugar, destacamos que algunos estudiantes han expuesto como causa de la elección la indagación sobre un asunto que aflora de su biografía escolar o de la formación académica en la Universidad, es decir, una preocupación que ya atesoraban antes de su llegada a los centros de prácticas. Este alumno, por ejemplo, refiere a una motivación radicada en su formación inicial, concretamente en la especialidad que cursa:

El tema que he elegido es muy específico. Dado que soy alumno de la especialidad de Educación Física y he tenido la suerte de que mi tutor en el colegio sea profesor de esta área, me ha parecido oportuno hablar de ello aquí. Voy a hacer especial incidencia en el uso de espacios y materiales para la práctica de gimnasia.

También descubrimos caminos en la exploración biográfica que son inversos: partiendo de lo que actualmente han observado y les ha interesado de su periodo de practicum, han reflexionado sobre cómo ese asunto pedagógico se comprendía o configuraba en su historia escolar.

En mi experiencia escolar, el material que más utilizábamos era el libro de texto. Para cada asignatura teníamos un libro y nos basábamos exclusivamente en él. Cosa que no daba cabida a que nosotros nos planteáramos preguntas sobre lo que aprendíamos, solo nos centrábamos en lo que los libros no decían.

No obstante, descubrimos que esta indagación retrospectiva se manifiesta para ellos dificultosa $y$, en algunos casos, han mostrado resistencias para acometer esta tarea. Indagando sobre los motivos, encontramos que algunos estudiantes no logran avanzar más allá de lo evidente o superfluo en las relaciones entre la experiencia biográfica y la configuración de teorías pedagógicas, probablemente porque exige un nivel alto de reflexión. Sin embargo, cuando lo consiguen, la exploración biográfica muestra una potencialidad grande para movilizar las ideas explícitas e implícitas que los aspirantes a maestros poseen sobre los asuntos pedagógicos, así como para problematizar el asunto objeto de reflexión:

La visión que actualmente tengo de la atención a la diversidad se debe a los comentarios que he ido escuchando durante los 3 años que llevo en la facultad. De lo contrario, estaría convencida de que solo hay una forma de hacer las cosas: que el que se queda por el camino, repite curso o no saca buenas notas es porque no se esfuerza lo suficiente, no porque la metodología no se adapte a sus necesidades. Al fin y al cabo, es lo que he visto durante toda mi vida.

En cualquier caso, las dificultades mencionadas buscan superarse a través de un espacio de diálogo inicial sobre la formulación de la preocupación, de la conexión con referentes teóricos y del propio proceso de indagación con imágenes, que abordaremos posteriormente. El desafío en este momento reside en aprender a mirar y mirar-se de nuevo, planteando interrogantes sobre lo que se hizo y cómo esa experiencia escolar vivida puede cimentar las convicciones pedagógicas que actualmente mantienen sobre la enseñanza y la escuela. Las palabras siguientes muestran cómo se despliega este proceso de aprender a mirar-se de nuevo:

[Hablando de los contenidos estereotipados] He crecido con estereotipos: aunque yo jugase con los juguetes de mi hermano e hiciese atletismo, estaba expuesta a las influencias de las películas Disney y de la sociedad, por lo que con 6 o 7 años tenía muy claro qué debía hacer como niña que era. A medida que fui creciendo, fui haciendo cosas cada vez más típicas de las niñas. Sin embargo, considero que nuestra sociedad se encuentra en un momento de cambio. Disney empieza a introducir princesas 
guerreras, las revoluciones feministas ponen "sobre la mesa" todo lo que se ha dado por sentado durante toda la vida...

\section{¿Qué aprendemos de la Photovoice?}

La elaboración de las fotografías por parte de los estudiantes se presentó como una estrategia valiosa para la documentación y construcción de narrativas sobre el asunto de indagación (Wang y Burris, 1994). En primer lugar, mirar a través de la lente de la cámara, facilitó que el alumnado dedicase un tiempo a la observación y reflexión de la vida del aula, acciones ambas con escasa presencia en un desarrollo del practicum en el que inician la intervención desde los primeros instantes. A continuación, mostramos un ejemplo ilustrativo:

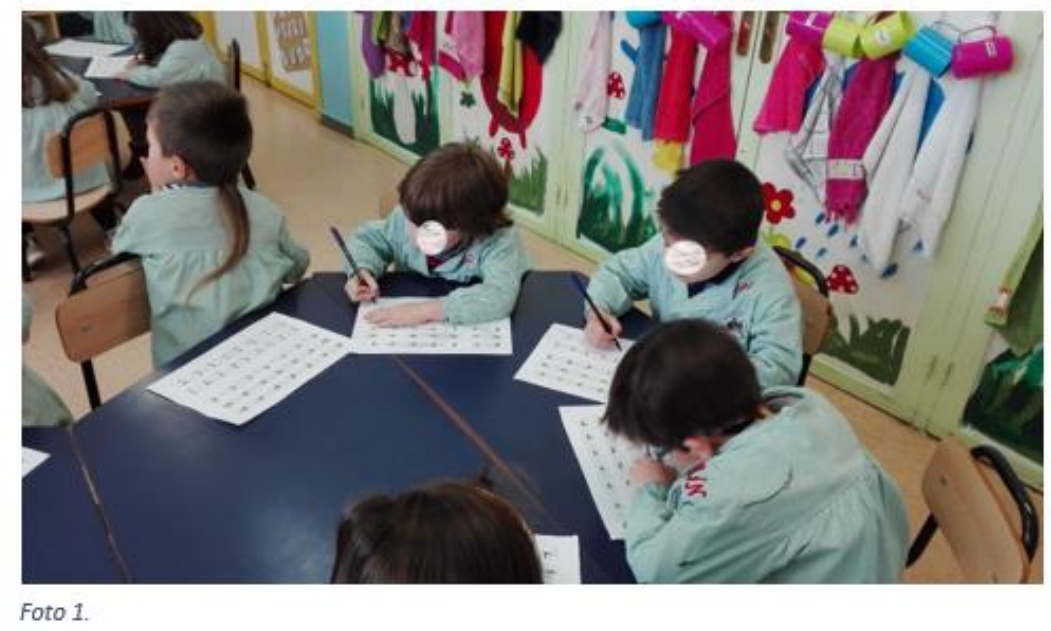

En la foto 1 , podemos observar un grupo de cinco niños. Todos ellos van vestidos con el babi del colegio y están haciendo una ficha de caligrafia; excepto uno, que ha terminado su tarea y está esperando a que acaben sus compañeros. En esta ocasión, este niño lleva un rato esperando, pero no es la primera vez que le pasa. Le ocurre todos los días y en todas las actividades que hacemos.

Imagen 1. Ejemplo de reflexión a partir de photovoice.

Durante el primer mes de estancia en el centro, esta alumna no había recogido en el diario ninguna apreciación sobre el uso del tiempo en el aula o sobre este alumno en concreto. Asimismo, tampoco era el asunto que le llevó a realizar la imagen pues buscaba documentar los materiales que se usan en el aula. Sin embargo, la fotografía la situó frente a una realidad que había permanecido oculta a su mirada y ante un niño que no había reclamado su atención. Estas imágenes permitieron visibilizar aquello que, a través de otros lenguajes, se ha mantenido invisible. Facilitó a la alumna des-familiarizarse con la vida del aula (Mannay, 2017), le permitió hacer de lo familiar, de aquello que está presente y ocurre con frecuencia en el aula (los diferentes ritmos del alumnado y que algunos de ellos se encuentren con periodicidad a la espera), algo extraño. Al mismo tiempo, se vio reforzada la idea de la fotografía como una herramienta compleja para registrar y visualizar sus ideas, preocupaciones e interpretaciones que incluso nos descubre nuevos caminos que ver, interpretar e imaginar alternativas (Wang y Burris, 1994). 
Por otro lado, podemos resaltar la preferencia del alumnado por realizar imágenes que recogen gráficamente los diferentes elementos sobre los que quieren indagar. No encontramos fotografías abstractas que hagan uso de la metáfora para abordar los temas. Únicamente podemos señalar un ejemplo en el que un alumnado utilizó las imágenes como evocación:

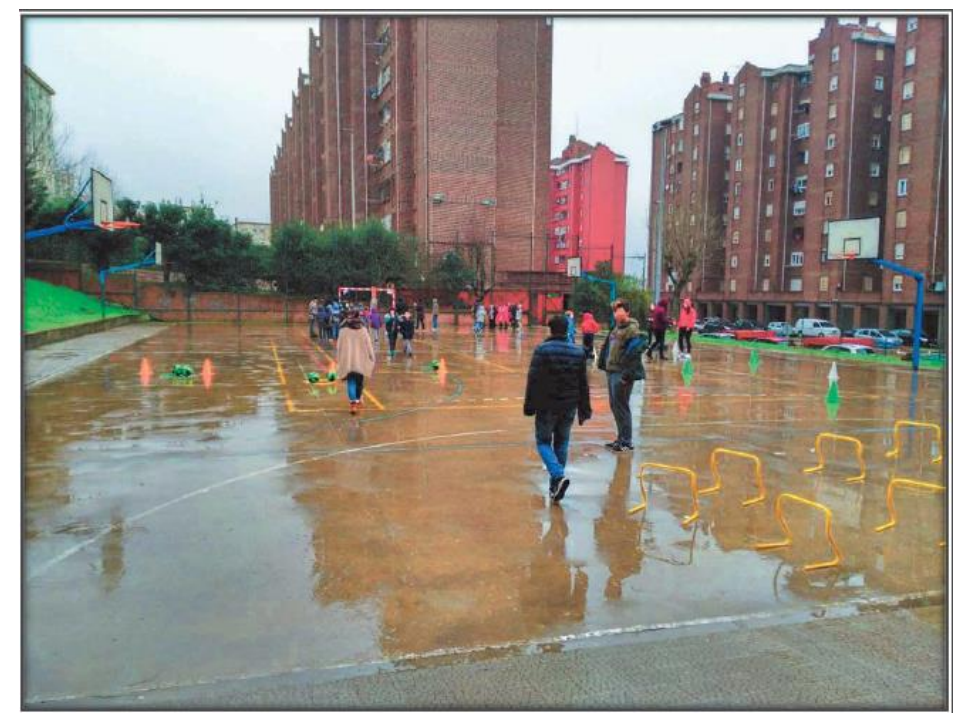

Imagen 2. Ejemplo de diálogo en el seminario a partir de photovoice.

El alumno presenta la primera imagen. Se ven caras de asombro que un compañero verbaliza en la pregunta ¿sobre qué va la imagen? Se inicia un diálogo sobre el sentido de la misma, la analizan desgranando sus elementos (niños, patio, lluvia, etc.). Tras esta lluvia de ideas, el alumno lee su diario: "Lo que estaba pasando en ese momento era que, durante el transcurso de una actividad, aprovechando un breve periodo de buen tiempo, estaba empezando a llover nuevamente y por tanto el juego iba a ser cancelado. Este instante (imagen) es justo antes de comunicárselo. Mi idea era intentar plasmar lo necesaria que es también la planificación en Educación Física, haciendo hincapié en la preparación de aquellas situaciones al aire libre." (diario de investigación).

En este ejemplo, la consideración de la imagen como fiel reflejo de la realidad fue puesta en cuestión en el transcurso del diálogo colectivo. El alumno no buscaba capturar la lluvia o el juego, sino sugerir un asunto de diálogo complejo (los procesos de planificación educativa) a través de una imagen evocativa. Una elección que fue objeto de diálogo colectivo al permitirnos pensar acerca de otras opciones de plasmar esta idea.

Este proceso no está exento de dificultades. Encontramos fotografías que ofrecieron escasas oportunidades de diálogo. Por ejemplo, una alumna aporta una fotografía en la que se observa una imagen general del aula. Si bien la imagen muestra algunos aspectos (distribución de espacios u organización de los grupos) no permite profundizar sobre su foco de indagación: la atención a la diversidad, ni responder a sus preguntas de indagación.

\section{¿Cómo son y evolucionan los procesos reflexivos recogidos en el diario?}

En este apartado, analizaremos la evolución reflexiva encontrada en los diarios, atendiendo a la reflexividad discursiva (descriptiva, explicativa o propositiva), así como a los niveles de reflexión respecto del conocimiento docente, según Larrivee (2008): reflexión superficial, reflexión pedagógica y reflexión crítica. 
Encontramos que un número no pequeño de estudiantes comienza su participación en esta propuesta realizando reflexiones superficiales sustentadas únicamente en la evidencia de su experiencia, pero no en el conocimiento pedagógico existente. Este tipo de reflexiones suelen formularse de manera descriptiva, con un nivel bajo de interpretación, valoración o crítica, abordando trivialmente los temas o asuntos descritos. Si bien esto restringe su mirada inicial sobre el asunto, comprobamos que ofrece un espacio futuro de reflexión amplio cuando se complementa con otras estrategias como los seminarios reflexivos. Presentamos un ejemplo de narración situadas en este nivel de reflexión:

En la pared donde los niños pueden chocarse se han puesto unas almohadillas blandas y que hacen que el golpe se quede en nada. Además de esta forma el color rojo es llamativo para los niños. Decir que la medida me parece genial ya que las posibilidades de que un niño se golpease eran bastante altas.

Dentro de este nivel de reflexión superficial, también englobamos aquella escritura orientada a explorar técnicamente el objeto de indagación, buscando la eficacia de las estrategias didácticas para lograr ciertos fines curriculares. Las preguntas que buscan guiar el proceso de reflexión de esta alumna (que se realiza ella misma) son un buen ejemplo de este enfoque técnico:

Preguntas de indagación sobre los materiales: ¿es necesario basar el aprendizaje en un material? ¿Qué material es el más indicado para enseñar? ¿Es recomendable que utilicen más las nuevas tecnologías? ¿Sería mejor dejar atrás el libro de texto y sustituirlo por aparatos electrónicos? ¿Es mejor que el material, lápices, goma, pinturas, etc.; lo proporcione el centro o que cada alumno lo traiga de casa?

Así, comprobamos cómo estos interrogantes están orientados a adquirir conocimientos, prácticas o respuestas únicas que permitan obtener una mayor eficacia. El interés último es obtener una "recomendación" que aplicar, sin cuestionar los aspectos éticos, metodológicos o epistemológicos que definen o enmarcan las diversas opciones.

En cualquier caso, comprobamos cómo los participantes inician sus primeros relatos en clave descriptiva siendo en el seno de los seminarios y en el diálogo compartido sobre las imágenes realizadas donde se supera esta tendencia inicial, pues acometen un trabajo analítico que les interroga e invita a establecer relaciones con referentes teóricos y las diversas interpretaciones surgidas. Lo ilustramos con los siguientes ejemplos, donde la imagen 2 responde a una primera reflexión sobre el asunto pedagógico realizada individualmente por la estudiante (fase 1), mientras la imagen 3 refiere al mismo tópico, pero tras la exposición y contraste de sus ideas en el seminario (fase 5 ). Como vemos, la estudiante camina hacia niveles más profundos de reflexión:

\footnotetext{
En este centro se utiliza la propuesta pedagógica Pompas de Jabón, de la editorial Algaida. Esta propuesta contiene todas y cada una de las indicaciones necesarias tanto para maestros como para padres. Está todo organizado, clasificado y planificado para determinadas sesiones y periodos de tiempo. Esta propuesta cuenta con diversos materiales, cuentos, posters para la clase, DVDs, fichas e incluso un peluche o mascota para la clase. Cada curso de infantil tiene unos personajes determinados. Un aspecto que me ha resultado chocante o anecdótico es que incluso vienen incluidas las coronas de cumpleaños, por lo que podemos interpretar que la propuesta no da pie a improvisación o creatividad alguna. En el aula se elaboran diferentes proyectos, pero estos proyectos no surgen como nos indica la propuesta educativa por proyectos de trabajo (PEPT), si no que dichos proyectos están previamente indicados por la propuesta, con determinados cuentos, y fichas. En el primer trimestre encontramos en el aula de tres años los indios, en 4 años China, y en 5 años la Prehistoria.

Otro de los materiales que utilizan son una serie de fichas de grafomotricidad de la editorial Anaya, se trata de una serie de pautas muy repetitivas, cada una con un dibujo de un monstruo que después deberán colorear.
}

Imagen 3. Ejemplo de reflexión inicial realizada individualmente. 
En el aula se elaboran diferentes proyectos, pero estos proyectos no surgen como nos indica la propuesta educativa por proyectos de trabajo (PEPT), si no que dichos proyectos están previamente indicados por la propuesta, con determinados cuentos, y fichas. En el primer trimestre encontramos en el aula de tres años los indios, en cuatro años China, y en cinco años la Prehistoria.

En este tipo de material aparece todo completamente infantilizado, plagado de coloridos dibujos y caricaturas, sin mostrar apenas imágenes o fotografías reales. Además, cabe mencionar que los aprendizajes no están en absoluto contextualizados, lo temas a tratar surgen por el simple hecho de que la editorial lo decide así, y no se busca una unión real, práctica a los aprendizajes realizados en el aula.

Otro de los materiales que utilizan son una serie de fichas de grafomotricidad de la editorial Anaya, se trata de una serie de pautas muy repetitivas, cada una con un dibujo de un monstruo que después deberán colorear. Este material, resulta cansado y aburrido para los alumnos. Incluso la maestra muestra poco interés respecto a este material, ya que es muy repetitivo, sin embargo, han de realizar la totalidad de las fichas. Esto nos lleva a pensar que los alumnos están de alguna manera obligados a utilizar todo el material, ya que es un material adquirido por las familias, y en la mayoría de las ocasiones las familias demandan trabajo visible para comprobar y documentar lo que sus hijos han aprendido dentro del centro escolar.

Imagen 4. Ejemplo de reflexión tras un seminario dialógico.

De este modo, algunos alumnos que comienzan con reflexiones en niveles superficiales y técnicos transitan hacia este tipo de reflexión pedagógica más profunda gracias a las experiencias dialógicas con sus compañeros y las supervisoras. En síntesis, este tipo de narraciones se caracterizan por ir más allá de la descripción y justificar, explicar o interpretar los hechos, apoyándose en pruebas de la experiencia, pero también de la teoría y la investigación, como ilustra el ejemplo siguiente:

Quiero hablar sobre la influencia de las editoriales en los colegios. Desde hace años se observa una creciente influencia de las empresas que se dedican a realizar el material utilizado por los alumnos en las escuelas. "El libro de texto ha sido uno de los elementos omnipresentes en la escuela; un dispositivo tan consustancial a una forma de entender el proceso de enseñanza-aprendizaje que quizá algunos profesores no sabrían qué hacer sin él" (Trilla-Bernet, 2002). Algo similar está ocurriendo en las escuelas de infantil, he presenciado como comerciales de diferentes editoriales acudían al centro para presentar los materiales del próximo curso y venderles. El uso de estas herramientas me parece excesivo en esta escuela, ya que veo que esto está creando profesoras que están a falta de creatividad.

Observamos, en este caso, una narración más profunda en la que la estudiante se interroga críticamente sobre las prácticas que observa y trata de responder algunas de sus inquietudes nutriendo su mirada con lecturas que aportan una perspectiva ajena.

Finalmente, cabría reseñar aquellos casos, los menos profusos, que tratan de indagar sobre las implicaciones morales y éticas de sus prácticas educativas (¿son justas y respetuosas con todo el alumnado?), comprendiendo la importancia del contexto social y político en el que éstas se desarrollan. 
De hecho, el lenguaje simple y almibarado ha llegado a ser considerado una característica propia de la Literatura Infantil y Juvenil para algunos autores, según Mínguez (2011). Sin embargo, el lenguaje no ha de ser simple, sino sencillo y adecuado a la edad del destinatario. Como conclusión general, me gustaría señalar que la infantilización es una de las grandes lacras con las que tiene que enfrentarse la Educación Infantil. Si conseguimos prescindir de ella; o, al menos, minimizar su impacto en los más pequeños, podremos formar y preparar ciudadanos democráticos, participativos, empáticos, reflexivos y con pensamiento crítico.

Como vemos, la preocupación de esta alumna con respecto a los contenidos escolares es grande, y entiende que tradicionalmente la cultura escolar, en su afán por "preservar" a la infancia de los peligros externos, ha tendido evitar temas conflictivos y también a no representar intereses y conocimientos de colectivos minoritarios, alejando a la institución educativa del objetivo de promocionar los ideales democráticos. En definitiva, sobresale en esta narración un nivel crítico de reflexión.

\section{Conclusiones}

Sintetizamos algunos elementos medulares de la propuesta que contribuyen a enriquecer la reflexión sobre las características irrenunciables que ha de contener una iniciativa de formación práctica de docentes.

En primer lugar, esta propuesta se sustenta en el poder del conflicto para generar movimiento (Sierra et al., 2017), en tanto en cuanto la tensión y la disonancia movilizan la acción, el cuestionamiento, la búsqueda de respuestas y de alternativas de actuación, que se transforman en posibilidades de aprendizaje y de desarrollo profesional. Por ello nuestra iniciativa se vertebra alrededor de un asunto pedagógico que los estudiantes tienen que confrontar reflexivamente.

De otro lado, observamos resistencias y conflictos en la exploración biográfica, donde los participantes experimentan dificultades para releer su biografía y comprender que el bagaje educativo que se edificó durante su experiencia escolar es responsable de muchas de sus teorías pedagógicas. La literatura (Clandinin y Connelly, 2000; Williams y Grierson, 2016) avala nuestra convicción de que esta mirada retrospectiva puede ser muy fructífera para reorientar la acción y el pensamiento docente, y quizá lo que podemos aprender de nuestra experiencia es la necesidad de dedicar más tiempo a esta tarea y diseñar momentos de indagación más estructurados.

Asimismo, se ha reconocido el valor de las imágenes para aprender a mirar de nuevo, afrontando el reto de preguntarse sobre el sentido de lo que habitualmente se vive y se hace (Couldry, 2010; Dreher, 2012). Sin embargo, también corroboramos que ofrecer espacios en los que los docentes en formación tienen voz es indispensable, pero no suficiente, pues el mero uso de la fotografía no empodera a los participantes. El principal valor de esta estrategia radica en las posibilidades de diálogo, negociación e interpretación que brinda, siempre que se ofrezcan los espacios necesarios para este fin (Fairey, 2017).

Asimismo, se corrobora una evolución reflexiva en el discurso de la mayoría de participantes gracias a la participación en los seminarios, donde la mayor parte termina la propuesta formativa situándose ante el tópico desde una posición exploratoria, abierta y orientada a la mejora de la práctica. De hecho, comprobamos cómo los participantes inician sus primeros relatos en clave descriptiva siendo en el seno de los seminarios y en el diálogo compartido sobre las imágenes realizadas donde se supera esta tendencia inicial, pues acometen un trabajo analítico que les interroga e invita a establecer relaciones con referentes teóricos y 
las diversas interpretaciones surgidas. Esta narración, más compleja y profunda, se ve influida por los conocimientos e interrogantes pedagógicos que han ido incorporando en su formación inicial (Susinos y Saiz, 2016). En síntesis, resulta irrenunciable plantear procesos dialógicos que se conviertan en catalizadores para el cambio (Fairey, 2017). En efecto, esta preocupación por situar los dilemas de los estudiantes en el centro de la formación docente es otra de las prospectivas que plantea este estudio. Finalmente, reconocemos el valor de la escritura no solo para relatar la experiencia, sino para rehacerla y para construir conocimiento (Badenhorst et al., 2016).

\section{Referencias}

Badenhorst, C., Mcleod, H., Vaandering, D., Li, X., Joy, R., Penney, S., Pickett, S. y Hesson, J. (2016). The journey between there and here: stories of a faculty writing group. Canadian Journal of Education, 39(1), 1-26.

Bautista, A., Rayón, L. y de las Heras, A. M. (2018). Imágenes experienciales y foto-elicitación en la formación del profesorado. Educatio Siglo XXI, 36(2), 135-162.

Beavers, E., Orange, A. y Kirkwood, D. (2017). Fostering critical and reflective thinking in an authentic learning situation. Journal of Early Childhood Teacher Education, 38(1), 3-18.

Clandinin, M. y Connelly, J. (2000). Narrative inquiry: experience and story in qualitative research. San Francisco: The Jossey-Bass education series.

Conklin, H. (2008). Modeling Compassion in critical, justice-oriented Teacher Education. Harvard Educational Review, 78(4), 652-674.

Contreras, J. y Pérez de Lara, N. (2010). Investigar la experiencia educativa. Madrid: Morata.

Cook, K. y Buck, G. (2010). Photovoice: A community-based socioscientific pedagogical tool. Science Scope, 33(7), 35-39.

Couldry, N. (2010). Why Voice Matters: Culture and Politics after Neoliberalism. London: Sage.

Dreher, T. (2012). A partial promise of voice: Digital storytelling and the limits of listening. Media International Australia, Australia, 142(1), 157-166.

Edwards, M., Perry, B., Janzen, K. y Menzies, C. (2012). Using the artistic pedagogical technology of photovoice to promote interaction in the online post-secondary classroom the students' perspective. Electronic Journal of e-Learning, 10(1), 32-43.

Eksi, G. y Güngör, M. (2018). Exploring the use of narratives to understand pre-service teachers' practicum experiences from a sociocultural perspective. Australian Journal of Teacher Education, 43(4), 159-174.

Fairey, T. (2017). Whose photo? Whose voice? Who listens? 'Giving,'silencing and listening to voice in participatory visual projects. Visual Studies, 33(2), 111-126.

Flick, U. (2014). La gestión de la calidad en investigación cualitativa. Madrid: Morata.

Gale, K. y Wyatt, J. (2007). Writing the incalculable: A second interactive inquiry. Qualitative Inquiry, 13(6), 787-807.

Gan, Z. y Lee, F. K. (2015). Understanding ESL student teachers' learning of classroom practices in the practicum: a case study in Hong Kong. The Asia-Pacific Education Researcher, 25(2).

Gibbs, G. (2012). El análisis de datos cualitativos en Investigación Cualitativa. Madrid: Morata. 
Kelchtermans, G. (2009). Who I am in how I teach is the message: self-understanding, vulnerability and reflection. Teachers and teaching: Theory and practice, 15(2), 257-272.

Kilgo, C., Sheets, J. y Pascarella, E. (2015). The link between high-impact practices and student learning: Some longitudinal evidence. Higher Education, 69(4), 509-525.

Kvale, S. (2011). Las entrevistas en investigación cualitativa. Madrid: Morata.

Larrivee, B. (2008). Development of a tool to assess teachers' level of reflective practice. Reflective Practice: international and multidisciplinary perspectives, 9(3), 341-360.

Lichty, L. (2013). Photovoice as a pedagogical tool in the community psychology classroom. Journal of Prevention and Intervention in the Community, 41(2), 89-96.

Mannay, D. (2017). Métodos visuales, narrativos y creativos en investigación cualitativa. Madrid: Narcea.

Mule, L. (2006). Preservice teachers' inquiry in a professional development school context: Implications for the practicum. Teaching and teacher education, 22(2), 205-218.

Novak, D. (2010). Democratizing qualitative research: Photovoice and the study of human communication. Communication Methods and Measures, 4(4), 291-310.

Parrilla, Á., Raposo, M., Martínez-Figueira, E. y Doval, M. I. (2017). Materiales didácticos para todos: el carácter inclusivo de fotovoz. Educatio Siglo XXI, 35(3), 17-38.

Peirce, C. (1986). La ciencia de la semiótica. Buenos Aires: Nueva Visión.

Prins, E. (2010). Participatory photography: A tool for empowerment or surveillance? Action Research, 8(4), 426-443.

Rapley, T. (2014). Los análisis de la conversación, del discurso y de documentos en investigación cualitativa. Madrid: Morata.

Richardson, L. y St. Pierre, E. (2005). Writing: A Method of Inquiry. En D. Norman e Y. Loncoln (Eds.), Handbook of Qualitative Research (p. 959-978). Thousand Oaks, Ca: Sage.

Rivas, I., Leite, A. y Cortés, P. (2014). Formación del profesorado y experiencia escolar: las historias de vida como práctica educativa. Praxis educativa, 18(2), 13-23.

Susinos, T. y Saiz Linares, Á. (2016). Los problemas pedagógicos son mis aliados. El practicum como un proceso de reflexión e indagación colaborativa. Revista de Investigación en Educación, 14(1), pp. 5-13,

Saiz, Á. y Susinos, T. (2017). Problemas pedagógicos para un Prácticum reflexivo de Maestros. Revista Complutense de Educacion, 28(4), 993-1008.Sierra, J., Caparrós, E., Molina, D. y Blanco, N. (2017). Aprender a través de la escritura. Los diarios de prácticas y el desarrollo de saberes experienciales. Revista Complutense de Educación, 28(3), 673688.

Simons, H. (2011). El estudio de caso: teoría y práctica. Madrid: Morata.

Sorensen, P. (2014). Collaboration, dialogue and expansive learning: the use of paired and multiple placements in the school practicum. Teaching and teacher education, 44, 128137.

Vassilaki, E. (2017). Reflective writing, reflecting on identities: The construction of writer identity in student teachers' reflections. Linguistics and Education, 42, 43-52.

Wang, C. y Redwood-Jones, Y. (2001). Photovoice ethics: Perspectives from Flint photovoice. Health education \& behavior, 28(5), 560-572. 
Wang, C. y Burris, M. A. (1994). Empowerment through photo novella: Portraits of participation. Health Education Quarterly, 21(2), 171-186, 1994.

Wenger, E. (2001). Comunidades de práctica. Aprendizaje, significado e identidad. Barcelona: Paidós.

Williams, J. y Grierson, A. (2016). Facilitating professional development during international practicum: understanding our work as teacher educators through critical incidents. Studying Teacher Education, 12(1), 55-69.

Wong, A. C. (2016). Considering Reflection From the Student Perspective in Higher Education. SAGE Open, 6(1), 1-9.

Zeichner, K. (2005). Los profesores como profesionales reflexivos y la democratización de la reforma escolar. Docencia, 25, 74-85. 